\title{
Prevalence of Depression and its Associated Factors Among Hypertensive Patients: A Cross Sectional Study
}

Divya Rayamajhi, ${ }^{1}$ Shreejana Wagle, ${ }^{1}$ Arun Karki ${ }^{1}$

${ }^{1}$ School of Health and Allied Sciences, Pokhara University

\begin{abstract}
Introduction: Mental health and physical health are association with each other's: poor mental health is a risk factor for chronic physical condition and it significantly impact on people's quality of life. The social determinants of health impact on both chronic physical condition and mental health. The purpose of this study was to determine the prevalence sub-clinical depression and factors associated with depression among the hypertensive out patients' department of hospitals in Pokhara.
\end{abstract}

Methods: A hospital based cross-sectional study design was conducted among 215 hypertensive patient visiting OPD ward of selected hospitals of Pokhara Metropolitan City. Depression levels were assessed using the Beck Depression Inventory-Ia (BDI) scale. Demographics and risk factors were assessed. Systematic random sampling was conducted for selecting hospitals and proportionate random sampling technique was used to make the sample representative of hospitals.

Results: Out of the total 215 hypertensive patients and around fifty-nine percentage were males and the mean age of respondents is $52 \pm 12.04$ years. Around one-third of the hypertensive patients had depression. The mean BDI-Ia score for depression status having respondent was $16.88 \pm 16.45$.

Conclusion: This study provides the evidence of depression is associate with hypertensive patient's socio-demographic factors such as sex, age, marital status, employment and income and behavioral factors. Hypertensive patients should be encouraged to increase their physical activities and family support.

Keywords: Depression, hypertension, patients

\section{INTRODUCTION}

Non communicable diseases are coined as chronic disease which are slow progressive with prolong effect and long lasting which are the result of combination of genetic, physiological, environmental and behaviors factors. According to WHO noncommunicable diseases accounted for $71 \%$ (41 million) of a total of 57.7 million deaths globally. Of these, $80 \%$ (32.8 million) were attributed to cardiovascular diseases, diabetes, cancers, and chronic respiratory diseases. ${ }^{1}$ About $80 \%$ of these NCD deaths (28 million) were recorded in low- and middle-income countries. ${ }^{2}$

Depression is a mental illness that influences the whole individual and characterized through loss of activity or pleasure, depressed mood, emotions of guilt or low self-worth, disturbed sleep or appetite, low energy, and terrible concentration. It is a treatable circumstance and can motive serious problems if left untreated. Chronic forms of morbidity like mental disorders and hypertension, impacts in the burden of disease in the developing world. ${ }^{3-4}$ World Health Organization (WHO) states that depression is the main cause of disability as measured by Years Lived with Disability (YLDs) and the fourth leading contributor to the global burden of disease and will be the second main contributor by the year $2020 .^{5}$
Hypertension has been emerging rapidly as a major public health problem in developing countries. Several factors contribute in hypertension including genetic factors, psychosocial factors, and behavioral factors. One of the psychosocial factors is depression, which is associated with variety of known CVD risk factors. ${ }^{6-7}$ The mechanism between hypertension and depression is complex. Patients with chronic illness, like hypertension, may experience negative emotions that in these patients increase the risk of mental disorders, most commonly depression and anxiety disorders. $^{8-9}$

The studied aims to find out prevalence of depression and factors associated with depression among hypertensive patients of selected hospitals in Pokhara Metropolitan City.

\section{METHODS}

This was cross sectional study in four hospitals of Pokhara, Nepal from August 2018 to October 2018. Hospitals were selected through systematic random sampling and proportionate random sampling technique was used according to hypertensive patients

Correspondence: Arun Karki, School of Health and Allied Sciences, Pokhara University, E-mail: akarkiarun@gmail.com 
flow in outpatient department of each hospital. Two hundred and fifteen hypertensive patient's aged 18 to 65 years were selected from both government and private hospitals.

Ethical approval was taken from the Institutional Review Committee, Pokhara University. Along with this approval taken from concern hospital and written informed consent was obtained from the participants. Anonymity, confidentiality, and privacy of information was maintained. If any misconception or risk behavior was found among participants during the study, then they provide suggestion for maintain healthy behavior for prevention of complication related to hypertension.

\section{Operational Definition}

\section{Socio-demographic and behavioral information}

Participants were interviewed and taking information regarding age, sex, ethnicity, family type, education, monthly income, physical activity, diet and life style factors (e.g. smoking and alcohol intake) were collected.

\section{Disease related information}

Participants were interviewed about disease related information (e.g anti- hypertension medication, duration of diagnosis disease, complication and psychiatric related medication and family history) were collected.

\section{Depression}

Depression assessments were made via Beck Depression Inventory (BDI-Ia). The BDI-Ia is a scale of 21 items with four response options, which assesses and quantifies the number of depressive symptoms across broad domains such as sadness, hopelessness, feeling of guilt, changes in sleep, and appetite. Patients was asked to recall events from the week before the interview. Items are scored $0-3$ with an instrument range of 0 to 62. The BDI-la is validated for use in Nepal and free access. ${ }^{10}$ Clinical based validation of the BDI in Nepal, a score of 20 or greater advises moderate depression symptoms with the need intervention (sensitivity $=0.73$, specificity $=0.91$ ). ${ }^{10}$ Therefore, in this study, we refer BDI $\geq 20$ as "depression" and BDI $\leq 20$ as "non depression" in categorical analyses.

\section{RESULTS}

Table 1: Socio-Demographic characteristics of participants

\begin{tabular}{lcc}
\hline Characteristics & Frequency $(\mathrm{n})$ & Percentage (\%) \\
\hline Age (Years) & & \\
$<44$ & 70 & 32.6 \\
$44-56$ & 73 & 34.0 \\
$\geq 57$ & 72 & 33.5 \\
Mean Age= 52 \pm 12.04 years & & \\
Sex & & \\
Male & 126 & 58.6
\end{tabular}

\begin{tabular}{|c|c|c|}
\hline Female & 89 & 41.4 \\
\hline \multicolumn{3}{|l|}{ Ethnicity } \\
\hline Upper caste & 127 & \\
\hline Janajati & 47 & 2 \\
\hline Dalit & 29 & \\
\hline Others & 12 & 5 \\
\hline \multicolumn{3}{|l|}{ Marital Status } \\
\hline Married & 189 & \\
\hline Never married/single & 26 & \\
\hline \multicolumn{3}{|l|}{ Family Type } \\
\hline Joint & 124 & \\
\hline Nuclear & 91 & \\
\hline \multicolumn{3}{|l|}{ Education } \\
\hline Illiterate & 43 & 2 \\
\hline Able to read or write & 17 & \\
\hline Primary level & 56 & \\
\hline Secondary level & 60 & \\
\hline Graduate and above & 39 & \\
\hline \multicolumn{3}{|l|}{ Employment status } \\
\hline Unemployed & 61 & \\
\hline Service & 50 & \\
\hline Self-employed & 40 & \\
\hline Agriculture & 40 & \\
\hline Others & 24 & \\
\hline \multicolumn{3}{|c|}{ Monthly income of the family } \\
\hline$\geq$ Nrs. $25,000 \mathrm{Nrs}$ & 121 & \\
\hline$<$ Nrs. $25,000 \mathrm{Nrs}$ & 94 & \\
\hline \multicolumn{3}{|c|}{ Family support in treatment } \\
\hline Yes & 205 & \\
\hline No & 10 & \\
\hline
\end{tabular}

Table 1 illustrates socio- demographic characteristics of two hundred fifteen respondents. The proportion of age group roughly equal among three groups and median age of respondent was $52 \pm 12$. More than half were male respondent and nearly sixty percent of participants belonged to higher caste. Nearly eighty percentage of the respondents were married. More than the half belongs to joint family and nearly twenty-eight percentage respondent complete the secondary level education and followed by primary level education and illiterate respondent were $20 \%$. The proportion of occupation status is nearly twenty-nine percentages were unemployed and the proportion of self-employed and agriculture are equal. More than a half respondent's family income is equal to NRs. $25,000 /-$.

Table 2: Behavioral status of participants

\begin{tabular}{lcc}
\hline Characteristics & Frequency $(\mathrm{n}=215)$ & Percentage $(\%)$ \\
\hline $\begin{array}{l}\text { History of smoking } \\
\text { Never smoker }\end{array}$ & 141 & 65.6
\end{tabular}




\begin{tabular}{lcc} 
Ex-smoker & 31 & 14.4 \\
Current smoker & 43 & 20.0 \\
History of alcoholism & & \\
Never alcoholic & 127 & 59.1 \\
Ex-alcoholic & 32 & 14.9 \\
Current alcoholic & 56 & 26.0 \\
Physical activity & & \\
$<150$ minutes/ week & 115 & 53.5 \\
$\geq 150$ minutes/ week & 100 & 46.5 \\
Fruits and green vegetables & & \\
$<2$ servings/ day & 114 & 53.0 \\
$\geq 2$ servings/ day & 101 & 47.0 \\
\hline
\end{tabular}

Table 2 Behavioral status respondent shows that most of respondent never smoke and drink alcohol in their life. The proportion of physical activity less than 150 minutes/week and more than equal to 150 minutes/week are nearly equal. Fruits and vegetables consumption less than 2 servings/day and more than equal to 2 servings/day are also nearby equal.

Table 3: Disease related characteristics of participants

\begin{tabular}{lcc}
\hline \multicolumn{1}{c}{ Characteristics } & Frequency $(\mathrm{n}=215)$ & Percentage $(\%)$ \\
\hline Anti-hypertensive Medication & 136 & 63.3 \\
Yes & 79 & 36.7 \\
No & \\
Duration of diagnosed hypertension & \\
$\geq 3$ years & 134 & 62.3 \\
$<3$ years & 81 & 37.7 \\
Family history of hypertension & & \\
No & 116 & 54.0 \\
Yes & 99 & 46.0 \\
Any chronic illness & & \\
No & 123 & 57.2 \\
Diabetes & 58 & 27.0 \\
Thyroid/ Uric acid & 12 & 5.6 \\
Asthma & 8 & 3.7 \\
Others & 14 & 6.5 \\
Use of anti-depressants & & \\
Yes & 17 & 7.9 \\
No & 198 & 92.1 \\
Sleep duration & & \\
$\geq 6$ hours/day & 141 & \\
$<6$ hours/day & 74.6 \\
\hline
\end{tabular}

Table 3 shows that more than sixty-three percentage respondents take anti-hypertensive medicine. The average period of diagnosed hypertension among the participants was $3 \pm 5.7$ years. Most of respond have not family history of hypertension and any chronic illness. Minimum respondent use anti -depressants medicine and near about sixty-six percentages have greater than or equal to six hours per day sleep duration.
Table 4: Status of depression among participants

\begin{tabular}{lccc}
\hline Characteristics & BDI Score & Frequency $(\mathrm{n})$ & Percentage $(\%)$ \\
\hline Depression & $\geq 20$ & 78 & 36.3 \\
No Depression & $<20$ & 137 & 63.7 \\
\hline
\end{tabular}

Table 4 shows the status of depression among the respondents, which show slight more than thirty-six percentages were found at depression status and rest of others at no depression status.

Table 5 : Proportion of participants who experienced depression scores

\begin{tabular}{lccc}
\hline \multirow{2}{*}{ BDI items } & \multirow{2}{*}{ Mean $\pm \mathrm{SD}$} & \multicolumn{2}{c}{ Depression } \\
& & (n) & $(\%)$ \\
\hline Total BDI-Ia score & $16.88 \pm 16.45$ & 78 & 36.3 \\
\hline
\end{tabular}

Table 5 indications the mean score of depression among hypertensive patients. The mean BDI-Ia score for depression status respondent was $16.88 \pm 16.45$. Association of Demographic Characteristics of Participants with Depression

Table 6 : Association of socio- demographic characteristics of participants with depression status

\begin{tabular}{|c|c|c|c|}
\hline Variables & $\begin{array}{l}\text { Depression } \\
(\mathrm{BDI} \geq 20)\end{array}$ & $\begin{array}{l}\text { No Depression } \\
(\mathrm{BDI}<20)\end{array}$ & $\mathrm{p}$-value \\
\hline \multicolumn{4}{|l|}{ Sex } \\
\hline Male & $34(27.0 \%)$ & $92(73 \%)$ & $0.001 * *$ \\
\hline Female & $44(49.4 \%)$ & $45(50.6 \%)$ & \\
\hline \multicolumn{4}{|l|}{ Age } \\
\hline$\leq 40$ years & $13(23.2 \%)$ & $43(76.8 \%)$ & $0.018 *$ \\
\hline$\geq 41$ years & $65(40.9 \%)$ & $94(59.1 \%)$ & \\
\hline \multicolumn{4}{|l|}{ Ethnicity } \\
\hline Upper caste & $45(35.4 \%)$ & $82(64.6 \%)$ & 0.757 \\
\hline Lower caste and others & $33(37.5 \%)$ & $55(62.5 \%)$ & \\
\hline \multicolumn{4}{|l|}{ Family Type } \\
\hline Joint & $41(33.1 \%)$ & $83(66.9 \%)$ & 0.252 \\
\hline Nuclear & $37(40.7 \%)$ & $54(59.3 \%)$ & \\
\hline \multicolumn{4}{|l|}{ Marital status } \\
\hline Married & $62(32.6 \%)$ & $128(67.4 \%)$ & $0.002 * *$ \\
\hline Single & $16(64.0 \%)$ & $9(36.0 \%)$ & \\
\hline \multicolumn{4}{|l|}{ Education } \\
\hline Never attended school & $36(60 \%)$ & $24(40 \%)$ & \\
\hline Basic level & $21(37.5 \%)$ & $35(62.5 \%)$ & $0.001 * *$ \\
\hline Secondary level & $15(25.0 \%)$ & $45(70.0 \%)$ & \\
\hline Graduate and above & $6(15.4 \%)$ & $33(84.6 \%)$ & \\
\hline \multicolumn{4}{|l|}{ Employment status } \\
\hline Unemployed & $42(49.4 \%)$ & $43(50.6 \%)$ & $0.001 * *$ \\
\hline Employed & $36(27.7 \%)$ & $94(72.3 \%)$ & \\
\hline \multicolumn{4}{|l|}{$\begin{array}{l}\text { Monthly income of the } \\
\text { family }\end{array}$} \\
\hline$<25,000 \mathrm{Nrs}$ & $44(46.8 \%)$ & $50(53.2 \%)$ & $0.005 * *$ \\
\hline
\end{tabular}




\begin{tabular}{lccc}
$\geq 25,000 \mathrm{Nrs}$ & $34(28.1 \%)$ & $87(71.9 \%)$ & \\
$\begin{array}{l}\text { Family support in } \\
\text { treatment }\end{array}$ & & & \\
Yes & $72(35.1 \%)$ & $133(64.9 \%)$ & $0.175 \#$ \\
No & $6(60.0 \%)$ & $4(40.0 \%)$ & \\
\hline
\end{tabular}

Table 6 showed the association between socio-demographic variables and depression status among the hypertensive respondents, age, marital status, education, employment and monthly income have significant association with depression.

Table 7: Association of behavioral characteristic with Depression status

\begin{tabular}{lccc}
\hline Variables & $\begin{array}{c}\text { Depression } \\
(\mathrm{BDI} \geq 20)\end{array}$ & $\begin{array}{c}\text { No Depression } \\
(\mathrm{BDI}<20)\end{array}$ & p-value \\
\hline $\begin{array}{l}\text { History of smoking } \\
\text { Ex- smoker }\end{array}$ & $15(48.4 \%)$ & $16(51.6 \%)$ & \\
Current smoker & $13(30.2 \%)$ & $30(69.8 \%)$ & 0.261 \\
Never smoker & $50(35.5 \%)$ & $91(64.5 \%)$ & \\
$\begin{array}{l}\text { History of alcoholism } \\
\text { Ex-alcoholic }\end{array}$ & $10(31.2 \%)$ & $22(68.8 \%)$ & \\
$\begin{array}{l}\text { Current alcoholic } \\
\text { Never alcoholic }\end{array}$ & $51(30.4 \%)$ & $39(69.6 \%)$ & 0.393 \\
$\begin{array}{l}\text { Physical activity } \\
<150 \text { minutes/week }\end{array}$ & $49(42.6 \%)$ & $66(57.4 \%)$ & $0.038^{*}$ \\
$\geq 150$ minutes/week & $29(29.0 \%)$ & $71(71.0 \%)$ & \\
$\begin{array}{l}\text { Fruits and green } \\
\text { vegetables }\end{array}$ & & & \\
$<2$ servings/ day & $49(43.0 \%)$ & $65(57.0 \%)$ & $0.030^{*}$ \\
$\geq 2$ servings/day & $29(28.7 \%)$ & $72(71.3 \%)$ & \\
\hline
\end{tabular}

Table 7 shows the association of behavioral characteristic with depression status, hypertensive respondent's physical activity and fruits \& vegetables consumption is significant association with depression.

Table 8: Association of disease-related characteristics of respondents with depression status

\begin{tabular}{lrrr}
\hline Variables & $\begin{array}{r}\text { Depression } \\
(\mathrm{BDI} \geq 20)\end{array}$ & $\begin{array}{c}\text { No } \\
\text { Depression } \\
(\mathrm{BDI}<20)\end{array}$ & p-value \\
\hline \multicolumn{2}{l}{ Anti-hypertensive } & & \\
Yes & $56(41.2 \%)$ & $80(58.8 \%)$ & 0.050 \\
No & $22(27.8 \%)$ & $57(72.2 \%)$ & \\
Duration of diagnosed hypertension & & \\
$<3$ years & $30(37.0 \%)$ & $51(63.0 \%)$ & 0.857 \\
$\geq 3$ years & $48(35.8 \%)$ & $86(64.2 \%)$ & \\
Family history of hypertension & & \\
Yes & $33(33.3 \%)$ & $66(66.7 \%)$ & 0.407 \\
No & $45(38.8 \%)$ & $71(61.2 \%)$ &
\end{tabular}

History of chronic illness

$\begin{array}{llll}\text { Yes } & 42(45.7 \%) & 50(54.3 \%) & 0.013^{*} \\ \text { No } & 36(29.3 \%) & 87(70.7 \%) & \end{array}$

Psychiatric illness in family

$\begin{array}{llcl}\text { Yes } & 15(75.0 \%) & 5(25.0 \%) & 0.001^{* *} \\ \text { No } & 63(32.3 \%) & 132(67.7 \%) & \\ \text { Sleep duration } & & & \\ <6 \text { hours/day } & 36(48.6 \%) & 38(51.4 \%) & 0.006^{* *} \\ \geq 6 \text { hours/day } & 42(29.8 \%) & 99(70.2 \%) & \end{array}$

Table 8 illustrates association behavioral characteristic and depression. Two variables were found statistically significant ( $\mathrm{p}<0.05)$. Physical activity $\left(\chi_{1}^{2}=4.285\right)$ and intake of fruits and vegetables $\left(\chi_{1}^{2}=4.285\right)$ were significantly associated with depression status.

\section{DISCUSSION}

As per the clinically validated cutoff in Nepal (BDI $\geq 20)$ is considered as depression requiring mental health intervention. ${ }^{10}$ A cross sectional study conducted in urban setting of Nepal shows the prevalence of undiagnosed depression was $15 \%{ }^{11}$ which is quite lower than this study. The cross-sectional study based on country-representative data obtained from WHO's World Health Survey (WHS) shows that the prevalence of being ever diagnosed with depression was highest in Nepal (38.7\%). ${ }^{2}$ Socio-demographic variables like age, sex, marital status, education, employment status and monthly income were association with depression and all these variables are also found to be significantly associated with hypertension, ${ }^{3,13,14}$ which shows that both the conditions i.e. hypertension and depression, shares a common pathway. This study showed the higher depression status among participants who never attended school in their lifetime than those who attended $(\mathrm{p}=0.015$, $\mathrm{OR}=3.240, \mathrm{CI}=1.261-8.321$ ). Illiteracy, being female and ageing had a direct relationship with depression in this present study, which is similar to the cross-sectional study conducted at urban setting of Nepal. ${ }^{11}$

In this study, depression used to be in increasing style with the increase in age however longitudinal study conducted in Europe ${ }^{15}$ and a cross-sectional find out about in Netherland ${ }^{6}$ has said the decreasing trend of depression with the increase in age. Elevated depression scores have been greater common amongst individuals who had been female or much less educated in this study, which is comparable to a seem to be AHEAD study trial carried out in USA. ${ }^{16}$

In this study, life-style related variables like physical activity and intake of fruits and green vegetables were found to be significantly associated with depression which is similar to the population- 
based prospective cohort study conducted in Washington ${ }^{13}$ secondary data analysis from cross-sectional survey in Austria ${ }^{18}$ and cross-sectional study in France. ${ }^{17}$ Participants consuming fruits and green vegetables less than 2 servings/day were found to be more depressed than who consumed more than or equal to 2 servings/day.

This study showed that there is no significant association between history of smoking and depression which is contrast to the study carried out at urban Nepal and teaching hospital of Nigeria. ${ }^{11,19}$ In this study there is no association between history of alcohol consumption and depression, which is similar to cross-sectional study of Brazil. ${ }^{20}$

In this study, participants having other chronic illness and participants having psychiatric illness in their family were more depressed than who had not, which is similar to the crosssectional study conducted in south-east Ethiopa. ${ }^{21}$ This study revealed that duration of diagnosed hypertension and family history of hypertension had no association with depression, which is similar to the cross-sectional study conducted in Nepal. Also, anti-hypertensive medications showed no association with depression, which is similar to the cross-sectional study in $\mathrm{Nepa}^{11}$ and a longitudinal survey in the USA. ${ }^{22}$

According to this study, short sleep period ( $\mathrm{p}=0.021, \mathrm{OR}=2.460$, $\mathrm{CI}=1.143-5.292$ ) was found significantly related to depression, that is comparable to the longitudinal study conducted in China

\section{CONCLUSION}

This study shows around one-third of the hypertensive patients had depression. The different socio-demographic factors, (i.e. sex, age, marital status, employment and income sources) and behavioral factor such as physical activity and fresh fruits intake connected factors were found considerably related to depression during this study. History of other chronic disease, psychiatric illness in family member and sleeping condition of patient also concern with the depression. This study suggest that treatment of hypertension is not only intervention for the quality of life of patient also screening of mental illness among chronic ill patients. Psychological and physical activities are also important part for the maintain of quality of life.

\section{REFERENCES}

1. World Health Organization. Noncommunicable disease Geneva. June, 2018.

2. World Health Organization (WHO) Projections of mortality and causes of death, 2015 and 2030. Bulletin of the World Health Organization. http://www.who.int/ healthinfo/global_burden_disease/projections/en/
3. Harzheim D, Klose H, Pinado FP, Ehlken N, Nagel C, Fischer $\mathrm{C}$, et al. Anxiety and depression disorders in patients with pulmonary arterial hypertension and chronic thromboembolic pulmonary hypertension. Respiratory research. 2013;14:104.

4. WHO.Depression.Availablefrom: http://www.who.int/ mental_health/management/depression/en/.

5. Schmauss M, Erfurth A. Indications for therapy using MAO inhibitors 1989 [cited 16]. 2-6]. Available from: http://www.ncbi.nlm.nih.gov/pubmed/2685853.

6. Ringoir L, Pedersen SS, Widdershoven JW, Pop VJ. Prevalence of psychological distress in elderly hypertension patients in primary care. Netherlands heart journal : monthly journal of the Netherlands Society of Cardiology and the Netherlands Heart Foundation. 2014;22(2):71-6.

7. Ginty A, Carroll D, Roseboom T, Phillips A, Rooij Sd. Depression and anxiety are associated with a diagnosis of hypertension 5 years later in a cohort of late middle-aged men and women 2013 [cited 27]. 187-90].

8. Kearney PM, Whelton M, Reynolds K, Muntner P, Whelton PK. Global burden of hypertension: analysis of worldwide data 2005. Available from: https://www.ncbi. nlm.nih.gov/pubmed/15652604.

9. DeJean D, Giacomini M, Vanstone M, Brundisini F. Patient Experiences of Depression and Anxiety with Chronic Disease: A Systematic Review and Qualitative Meta-Synthesis. Ontario Health Technology Assessment Series. 2013;13(16):1-33.

10. Kohrt BA, Kunz RD, Koirala NR, Sharma VD, Nepal MK (2002) Validation of a Nepali version of the Beck Depression Inventory. Nepalese Journal of Psychiatry 2: 123-130

11. Neupane D, Panthi B, McLachlan CS, Mishra SR, Kohrt BA, Kallestrup P. Prevalence of undiagnosed depression among persons with hypertension and associated risk factors: a cross-sectional study in urban Nepal. PloS one. 2015;10(2):e0117329.

12. Bishwajit G, O'Leary D, Ghosh S, Yaya S, Shangfeng T, Feng Z. Physical inactivity and self-reported depression among middle- and older-aged population in South Asia: World health survey. 2017. Available from: https://www. ncbi.nlm.nih.gov/pubmed/28454520

13. Delaney JA, Oddson BE, Kramer H, Shea S, Psaty BM, McClelland RL. Baseline Depressive Symptoms Are Not Associated With Clinically Important Levels of Incident Hypertension During Two Years of Follow-Up 01/13/2010 [cited 55]. 2010:[Available from: http://www.ncbi.nlm. nih.gov/pubmed/20065156,http://hyper.ahajournals.org/ content/hypertensionaha/55/2/408.full.pdf. 
14. Ma L, Tang Z, Sun F, Diao L, LiY, Wang J, etal. Risk factors for depression among elderly subjects with hypertension living at home in China. International journal of clinical and experimental medicine. 2015;8(2):2923-8.

15. Leigh JP, Du J.Are low wages risk factors for hypertension? European journal of public health.22(6):854-9.

16. Rubin RR, Gaussoin SA, Peyrot M, DiLillo V, Miller K, Wadden TA, et al. Cardiovascular disease risk factors, depression symptoms and antidepressant medicine use in the Look AHEAD (Action for Health in Diabetes) clinical trial of weight loss in diabetes. Diabetologia. 2010;53(8):1581-9.

17. Priou P, Le Vaillant M, Meslier N, Paris A, Pigeanne T, Nguyen XL, et al. Cumulative association of obstructive sleep apnea severity and short sleep duration with the risk for hypertension. PloS one. 2014;9(12):e115666.

18. Kautzky-Willer A, Dorner T, Jensby A, Rieder A. Women show a closer association between educational level and hypertension or diabetes mellitus than males: a secondary analysis from the Austrian HIS 2012 [updated May 30; cited 12]. 392]. Available from:http://www.ncbi.nlm.nih. gov/pubmed/22646095,
19. Igwe MN, Uwakwe R, Ahanotu CA, Onyeama GM, Bakare MO, Ndukuba AC. Factors associated with depression and suicide among patients with diabetes mellitus and essential hypertension in a Nigerian teaching hospital. African health sciences. 2013;13(1):68-77.

20. Wiehe M, Fuchs SC, Moreira LB, Moraes RS, Pereira GM, Gus M, et al. Absence of association between depression and hypertension: results of a prospectively designed population-based study. Journal of human hypertension. 2006;20(6):434-9.

21. Abdu Z, Kabeta T, Dube L, Tessema W, Abera M. Prevalence and Associated Factors of Depression among Prisoners in Jimma Town Prison, South West Ethiopia. Psychiatry journal. 2018;2018:5762608.

22. Simning A, Seplaki CL, Conwell Y. The association of a heart attack or stroke with depressive symptoms stratified by the presence of a close social contact. International journal of geriatric psychiatry. 2018;33(1):96-103.

23. Sun Y, Shi L, Bao Y, Sun Y, Shi J LL. The bidirectional relationship between sleep duration and depression in community-dwelling middle-aged and elderly individuals: evidence from a longitudinal study. 